\title{
Parameter Optimization and Simulation of NC Lathe Automatic Programming
}

\author{
Xiurong Zhu \\ College of Mechanical Engineering, Jilin Teacher's Institute of Engineering and Technology, \\ Changchun, Jilin, china 130052 \\ zxr67811@163.com
}

Keywords: CNC lathe; Automatic programming; Processing technology; Parameter optimization; Simulation processing

\begin{abstract}
CNC}$ lathe automatic programming and machining simulation parameters, summed up in the CNC lathe processing of complex shape programming procedure has advantages, and the complex parts processing as an example, the processing technology and $\mathrm{NC}$ program is complete, the use of CATIA V5 R20 plays an important role in the processing of parts. It is beneficial to the improvement of the machining process of the NC programmer, so as to solve the problems encountered in the numerical control machining. It is helpful for enterprises to save time and improve efficiency. The promotion of software automatic programming, so that more $\mathrm{CNC}$ practitioners to realize the importance of automatic programming software, and thus stimulate the interest of learning software automatic programming. The importance of automatic programming to the importance of automatic programming and the need for skilled use of automatic programming.
\end{abstract}

\section{Introduction}

With the continuous progress of numerical control technology, great changes have taken place between the properties and structure of $\mathrm{CNC}$ machine tools with traditional machine tool, the function of the system has been continuously strengthened, complex parts processing capacity is rising, especially when using the closed-loop control, intelligent control system development, and the error compensation system, machining accuracy has great progress than the general machine tool, and is constantly to a higher precision direction. It is a typical mechanical and electrical integration product, is the use of various disciplines of high-tech products, is a new automated equipment. It is an important basic industry to reflect the national comprehensive national strength and the national strategic position. The level of technology has become one of the important symbols to measure the level of a country's industrial modernization.[1]

In recent years, with the development of computer application technology, China has developed some automatic programming system, the advantages of automatic programming is: can the processing programming geometry of extremely complex parts, high programming speed, high precision, convenient operation, short cycle, easy computer examination, verification and checking tool position, track and the shape of parts etc.. Especially for complex parts, there is unparalleled technical and economic advantages, cannot be prepared manually completed procedures.[2]

Therefore, the automatic programming system of NC lathe is studied. In particular, the optimization and Simulation of machining parameters have important practical significance.

\section{Analysis and Parameter Optimization of Machining Process for Typical Parts of 2 CNC Lathe}

Analysis of Machining Process for Typical Parts of CNC Lathe. Part drawing as shown in 


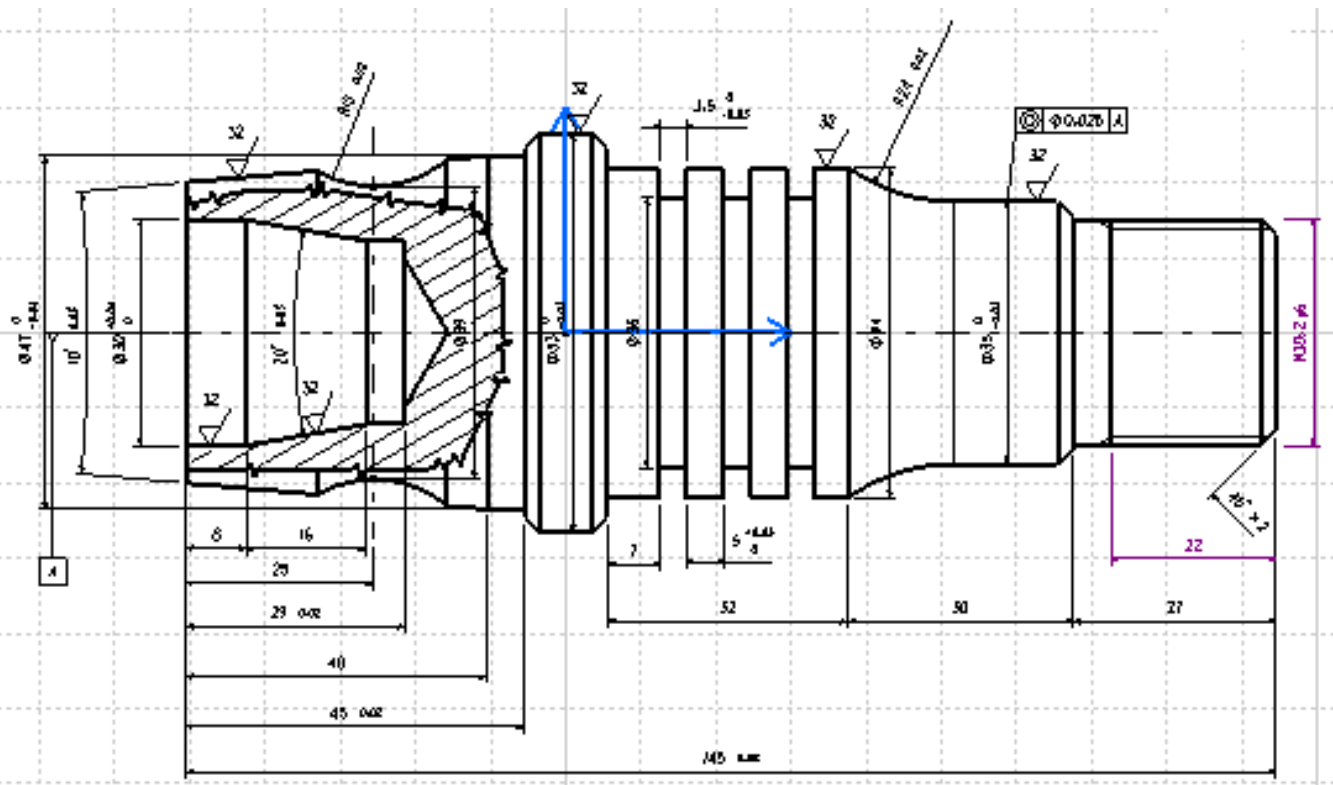

Figure 1. Part drawing of shaft

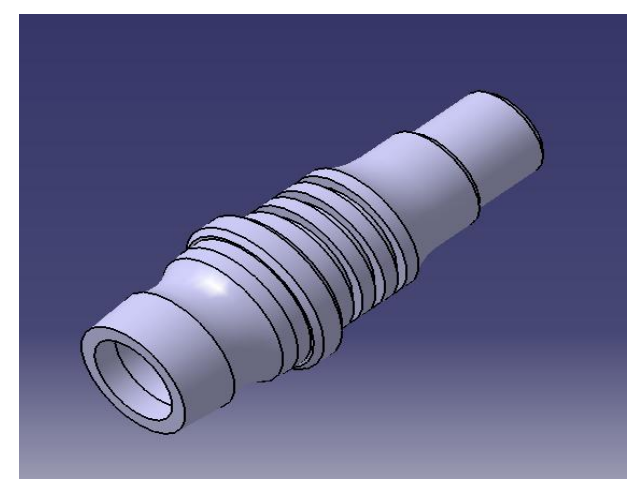

Figure 2. Entity diagram of axis

Accuracy Analysis. dimensional accuracy

In the case of the high precision size are: external circle Phi 30, Phi 35, Phi 44, Phi 53, Phi 47, length $22,27,30,32$ and $M 30 * 2$ threads. For the precision requirement, mainly through the accurate tool in the machining process, correct setting of cutter compensation and wear, as well as the correct system of suitable process and other measures to ensure.[3]

form and position accuracy, In this case, the main form and position accuracy requirements are: coaxial cylindrical with 53 axis and 35 axis, the shape and position tolerances, mainly through the mechanical precision adjustment of machine tool, and make public the reasonable process and work piece clamping and positioning to ensure positive and find measures. [4]

Blank Type. Parts for shaft parts, blank shaft with diameter of $60 \mathrm{~mm} * 150 \mathrm{~mm}$, precision grade IT8. The initial selection of the processing scheme for the rough car.[5]

Tool Selection. 1) 93 degree cylindrical turning tool machining and fine turning the outer contour; 2) slotting cutter; 3) tapping thread cutter; 4) 93 degrees hole lathe machining and fine car contour ; 5) with 20 twist drill. [6]

Table 1 Machining tool card

\begin{tabular}{|c|c|c|c|}
\hline Tool number & Tool specification name & Number & Machined surface \\
\hline T01 & 93degrees cylindrical turning tool & 1 & External contour \\
\hline T02 & slot knife 1 slots & 1 & groove \\
\hline T03 & Thread cutter & 1 & Tapping M30 thread \\
\hline T04 & 93 hole lathe & 1 & Inner contour \\
\hline T05 & With 20 twist drill & 1 & drill hole \\
\hline
\end{tabular}


Selective Processing Method. Part of the internal and external contours of the roughness requirements are Ra3.2, so in the turning process, you can use the first rough, and then the car program. Taking into account the rough part is $45 \#$ steel, the cutting performance is good and no hard surface, so in turning the nose arc of $\mathrm{R}=0.4$ tool, it can improve the surface roughness of the machined parts and reduce tool wear. In the processing of the inner hole and the inner contour, considering the precision and positioning machining precision, can adopt 93 DEG hole lathe, rough machining and finish machining of the car, so it can meet the requirements of machining precision. [7]

Machining Parameter Optimization. On determine the processing parameters in practical processing experience, machining precision and surface quality of the workpiece, the workpiece material properties and shape, rigid handle and other factors[8]

Feed Rate. (1) In order to improve the production efficiency, in the premise of ensuring the quality of the workpiece, the higher feed rate can be selected, and the feed rate of $F$ is $0.2 \mathrm{~mm} / \mathrm{r}$ Finishing feed speed generally select roughing feed speed of $1 / 2$. (2) when drilling $0.5 \mathrm{~mm} / \mathrm{r}$

Spindle Speed (N). Due to the processing of parts and materials for the 45\# steel, the cutting performance is good, the feed rate and cutting depth and the selected are relatively small, so the table reference, the cutting speed can be achieved, so the cutting speed of choice for $160 \mathrm{~m} / \mathrm{min}$. Therefore, when the milling cutter for machining parts, the spindle speed:

$$
n=\frac{1000 \times v}{\pi \times d}=800 \mathrm{r} / \mathrm{min}
$$

After calculation can be obtained, the roughing of the spindle speed can be chosen as $800 \mathrm{r} / \mathrm{min}$, the spindle speed is $1200 \mathrm{r} / \mathrm{min}$.

Cutting depth. The parts of the blank selection is $45 \#$ steel, so the cutting processing performance is good, the use of machine tools are CNC lathes, CNC lathe by considering the characteristics of actual performance and processing, the maximum value of the cutting depth is $1 \mathrm{~mm}$, and the machining surface roughness higher so, the need for rough and fine processing in the processing, so in rough machining, cutting depth MID choose $0.2 \mathrm{~mm}$, choose the precision machining precision machining allowance is $0.4 \mathrm{~mm}$. As a result of the machine tool feed quantity is $0.1 \mathrm{~mm} / \mathrm{r}$, so in order to improve the efficiency of processing, in rough machining, the choice of the contour of the direction of feed (ie FFP1) is $0.2 \mathrm{~mm} / \mathrm{r}$.

Table 2 Cutting three elements

\begin{tabular}{|l|l|l|l|}
\hline Processingmeethod & Spindle speed $(\mathrm{n} / \mathrm{min})$ & Feed rate $(\mathrm{mm} / \mathrm{r})$ & Cutting depth $(\mathrm{mm})$ \\
\hline Rough machining & 800 & 0.2 & 1.0 \\
\hline finish machining & 1200 & 0.1 & 0.4 \\
\hline
\end{tabular}

Workpiece machining coordinate system. Select the center of the upper surface of the workpiece as the origin of the workpiece coordinate system. The following diagram shows[9]

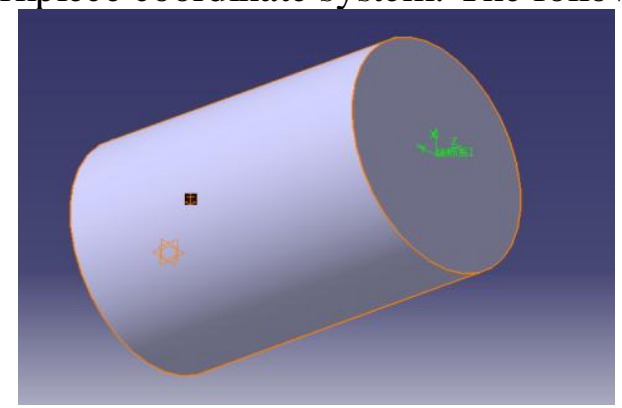

Figure 3. Determination of workpiece coordinate system 


\section{Simulation Processing}

Application of CATIA software for drawing and simulation processing.[10]

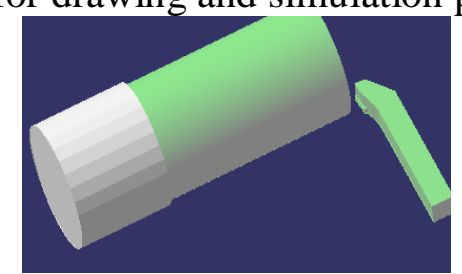

Figure 4. Rough machining simulation

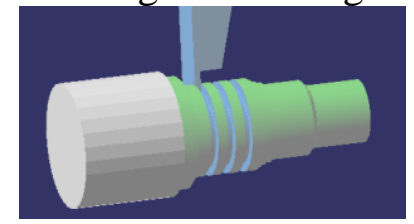

Figure 5. Slot machining simulation

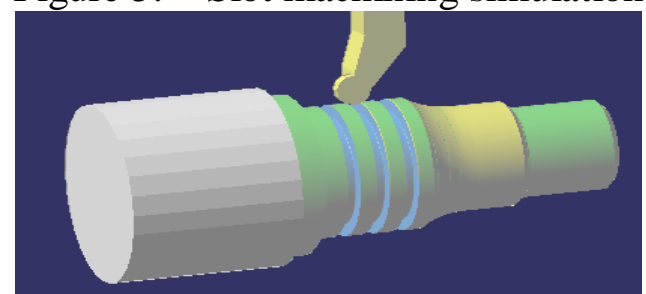

Figure 6. Finishing simulation

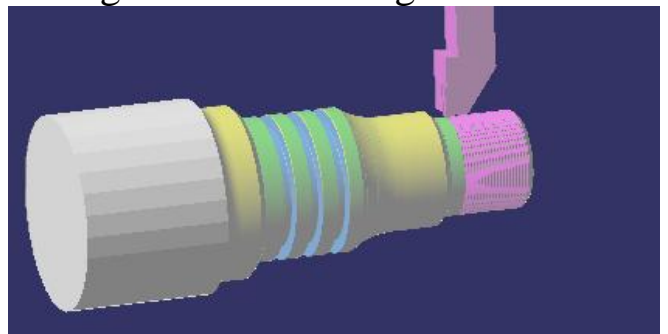

Figure 7. Thread machining simulation

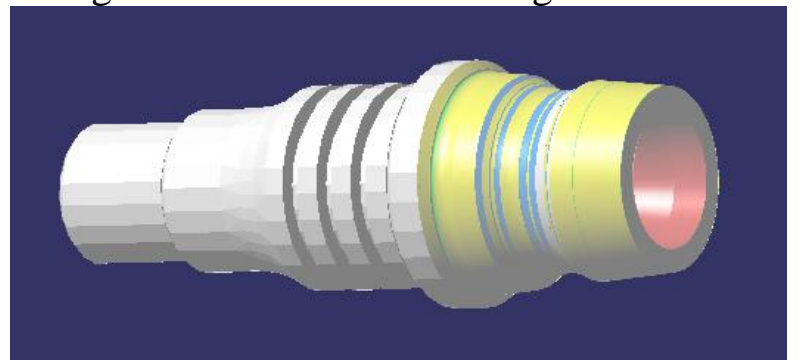

Figure 8. Simulation of the other side of the map

\section{Concluding Remarks}

Based on the research of automatic programming and Simulation of NC lathe, this paper finds out the optimization of processing parameters of complex parts in $\mathrm{NC}$ machine tools. According to the programming library of typical parts of NC lathe, the program can be compiled with reference to the relevant program in order to improve the programming efficiency.

1 is advantageous to the numerical control programming personnel processing technology enhancement, thus solves the enterprise numerical control processing the question which meets.

2 is conducive to processing parts to save time, improve efficiency.

3 is conducive to the promotion of software automatic programming, so that more CNC practitioners realize the importance of automatic programming software, and thus stimulate the interest of learning software automatic programming. 


\section{Reference}

[1] Guangzhen, Lu Jianxiang, NC technology and programming [M]. Beijing: Peking University press, 2015.08

[2] Meng Lingxia, Zhang Zhi, numerical control technology training course [M]. Beijing: National Defence Industry Press, 2014

[3] Tang Wenxian, introduction and improvement of CNC machining process [M]. Beijing: China Machine Press, 2013

[4] Wu Zhiguo, Huang Yunlin, and so on, CNC lathe programming 80 cases: the essence of the [M]. Beijing: Chemical Industry Press, 2014 (in Chinese)

[5] Lv Binjie, Gao Changyin, Zhao Wen (FANUC.SIEMENS), CNC lathe programming example of the essence of [M]. Beijing: Chemical Industry Press, 2011

[6] Ni Xiangming, CNC machine tools and CNC machining technology [M]. people's Posts and Telecommunications Press, 2011

[7] Sun Xingwei, Xue Xiaolan, FANUC programming and processing of CNC machine tools [M]. Beijing: China Water Conservancy and Hydropower Press, 2015 (in Chinese)

[8] Yunjie Zhang, Lijian Hao, CATIA V5-6 R2014 foundation design case. Tsinghua University Press, 2015.06

[9] Yunjie Zhang, Yunjing Zhang, CATIA V5 from to master. Tsinghua University Press, 2013, R21, entry, the

[10]Zhan Yi, CATIA V5R20 CNC machining tutorial [M]. Beijing: China Machine Press, 2013 